\title{
Nota do Fórum de Coordenadores de Programas de Pós-graduação em Saúde Coletiva sobre o novo Qualis Periódicos*
}

A Saúde Coletiva brasileira é uma área consolidada e em expansão, tanto em termos das atividades da pós-graduação quanto da pesquisa. Atualmente, além do inegável impacto da área no âmbito das políticas públicas no país, não somente a pesquisa em Saúde Coletiva produzida no Brasil alcança cada vez mais reconhecimento internacional, como a área está crescentemente envolvida em esforços internacionais, em particular, na América Latina e na África. É, portanto, uma área com forte inserção social e bastante madura do ponto de vista acadêmico.

Tal resultado tem como um dos seus pilares o apoio da Coordenação de Aperfeiçoamento de Pessoal de Nível Superior do Ministério da Educação - CAPES/MEC - expresso no suporte que vem sendo ofertado a várias iniciativas da área visando à formação de pessoal pós-graduado. Nesse contexto, o Fórum de Coordenadores de Programas de Pós-Graduação em Saúde Coletiva, desde a sua criação, há mais de uma década, vem se reunindo semestralmente, com a finalidade de discutir e deliberar sobre os diversos aspectos da pós-graduação na área, conferindo destaque à avaliação dos Programas. Em sua atuação, articula-se com a representação da área no âmbito da CAPES/MEC e com a Associação Brasileira de Pós Graduação em Saúde Coletiva - ABRASCO, desempenhando papel fundamental no desenvolvimento da área.

Este Fórum - envolvendo atualmente uma rede de mais de 50 cursos de pós-graduação em Saúde Coletiva distribuídos pelas distintas regiões do país - vem historicamente respondendo aos desafios e propostas para a pós-graduação brasileira, tendo refletido intensamente, ao longo dos últimos anos, sobre a avaliação no âmbito da CAPES, contribuindo nos planos conceitual e operacional para o seu aperfeiçoamento. Dentre os produtos gerados com base no espírito de diálogo e parceria com as instâncias de avaliação, o Fórum elaborou uma proposta para a reclassificação de periódicos, aprovada em sua reunião no primeiro semestre deste ano, realizada em junho em Recife (PE). Baseado em discussão densa e consistente, o Fórum examinou indicadores de produção, características de bases de indexação e propriedades de indicadores bibliométricos, produzindo um conjunto de critérios objetivando diferenciar os veículos qualificados e dar destaque a um elenco seleto de revistas científicas na- cionais da área, caracterizadas como periódicos maduros e fundamentais para o desenvolvimento do campo.

Ressaltamos que tal iniciativa não se caracteriza de forma alguma como "favorecimento" dos referidos veículos, mas, ao contrário, deriva do reconhecimento de características estruturais internas da Saúde Coletiva, área heterogênea disciplinarmente e com sub-áreas com possibilidades diversas de atingir um conjunto de leitores em outros países que não o Brasil: enquanto algumas sub-áreas da Saúde Coletiva têm crescente presença internacional, parte considerável da produção da área é, como deve ser, marcada por singularidades pelo fato de se debruçar sobre a realidade brasileira, tendo assim, em que pese sua indiscutível qualidade e relevância social, escasso interesse para platéias internacionais.

Tanto é assim que, ao se contemplar indicadores como o índice $\mathrm{H}$, calculado pelo consórcio Scimago com base nos dados da base Scopus, temos revistas nacionais que são comparáveis às suas congêneres européias e norte-americanas, e que por conta exatamente de sua qualidade são extremamente atrativas para os pesquisadores da área, que as privilegiam como veículo de difusão de sua produção. Para se dimensionar esta importância das revistas da área da Saúde Coletiva publicadas no país, há duas delas que se situam entre as $40 \%$ (considerando um universo de aproximadamente 14 mil revistas de todas as áreas do conhecimento de todas as partes do mundo) com melhor desempenho bibliométrico (medido pelo índice $\mathrm{H}$ ).

Em sua última reunião, realizada nos dias o1 e 02 de outubro de 2008, para além da questão específica do Qualis, o Fórum acolheu com satisfação as recentes modificações propostas na sistemática da avaliação, em particular a possibilidade de trabalhar com um critério de pontuação que considera a totalidade da produção científica, e não apenas aquela publicada em revistas em determinados estratos.

Contudo, o Fórum foi surpreendido pela não aprovação de sua proposta de qualificação de periódicos, assim como pela determinação recente da CAPES de que os estratos superiores (A1 e A2) da nova classificação não deveriam conter mais que 20\% dos artigos produzidos pela área. A aplicação irrestrita deste critério, arbitrário e sem sustentação conceitual ou bibliométrica, pode se revelar danosa para algumas áreas

\footnotetext{
* Documento gerado a partir de discussões realizadas no Fórum de Coordenadores de Programas de Pós-Graduação em Saúde Coletiva, reunido em Vitória, Espírito Santo, nos dias 1 e 2 de Outubro de 2008. http://www.abrasco.org.br/forumsaudecoletiva/index.php
} 
do conhecimento. No caso da Saúde Coletiva, compromete gravemente o projeto político-acadêmico desenhado pela área e coloca sob risco a árdua e indiscutível conquista de qualificação dos nossos periódicos.

O efeito da nova proposta de Qualis periódicos foi o rebaixamento de todos os periódicos nacionais relevantes, tomando como base a proposta elaborada pelo Fórum para a área de Saúde Coletiva, em particular deixando os estratos A1 e A2 sem nenhum periódico nacional relevante para o campo. A lógica utilizada gera ainda um grave problema lógico: apesar de seus excelentes indicadores bibliométricos, será impossível para os mais importantes periódicos da área ascender simultaneamente para o nível A, já que dois deles concentram aproximadamente $20 \%$ da produção da área. Considerando que o critério de percentual de distribuição por faixas não guarda qualquer relação objetiva com a qualidade dos periódicos, sendo meramente um artefato aritmético de ranqueamento, a nova classificação gera distorções que podem comprometer as conquistas e avanços da área no país.

Como seria esperado, a Política de Avaliação da Pós-Graduação e os critérios por ela definidos têm um poderoso papel indutor que ultrapassa o âmbito estrito dos programas. A classificação Qualis, por exemplo, passou a ser adotada como parâmetro de qualificação da produção de pesquisadores pelas agências de fomento e para a avaliação de professores pelas instituições de ensino. Foi exatamente o papel indutor do Qualis que levou à valorização e concentração da produção da Saúde Coletiva nos periódicos no país, e é pela mesma razão que a barreira artificial dos $20 \%$ pode impactar negativamente os periódicos mais consolidados na área.

Vale ressaltar também, que a política de ciência e tecnologia no país incluiu, nos últimos anos, o reconhecimento da importância de se ter revistas científicas fortes e reconhecidas nacional e internacionalmente. Fruto desta política, em particular na área da Saúde Coletiva, deu-se uma bem sucedida trajetória do periodismo científico nacional, que resultou no fortalecimento e concentração da produção em algumas revistas. Paradoxalmente, o cenário conquistado de revistas nacionais fortes, reconhecidas pela comunidade e com critérios altamente seletivos (algumas das revistas publicam somente $15-20 \%$ dos originais recebidos), será punido com a nova determinação. Isto mostra de forma inequívoca não apenas a arbitrariedade e incoerência já antes aludidas, mas a destrutividade da nova "cláusula de barreira" e sua insustentabilidade dentro da política de ciência e tecnologia do país.

A expulsão dos periódicos nacionais dos estratos superiores da classificação e o rebaixamento geral de todo o seu conjunto induz à interpretação por parte dos demais agentes de fomento que não a CAPES/MEC como um 'atestado de baixa qualidade' dos mesmos, sobretudo frente aos periódi- cos estrangeiros. Surpreende e preocupa muito este Fórum o desestímulo ao empenho do corpo nacional de editores de periódicos científicos da área e o impacto desta "cláusula de barreira" em toda a dinâmica da pesquisa, produção, disseminação de conhecimento e de ensino pós-graduado em Saúde Coletiva no país. Não é demais reiterar que, no caso da Saúde Coletiva, estamos lidando com periódicos que, produzidos no Brasil, têm inegável reconhecimento internacional, como atestam as medidas de impacto que os mesmos apresentam.

Em função do acima exposto, o Fórum de Coordenadores de Pós-graduação em Saúde Coletiva conclama a CAPES/MEC a reconsiderar sua determinação sobre limites percentuais por estratos, sem considerar especificidades que não podem ser subtraídas, e a acatar nossa proposta original de classificação para periódicos para a área de Saúde Coletiva. Fruto de anos de discussão e acúmulo no que concerne à natureza e às características da produção na área, tal classificação deriva da nossa trajetória de análise ampla e madura sobre a Política Nacional de fomento a pesquisa, gestão do conhecimento e ensino em pós-graduação em Saúde Coletiva que são substrato e expressão do que ora pleiteamos.

O fórum de Coordenadores da Saúde Coletiva reconhece que, inegavelmente, a CAPES tem desempenhado um papel fundamental no aprimoramento do sistema de pós-graduação no país. A máxima de que a CAPES é “constituída pela própria comunidade científica” tem garantido que os parâmetros de avaliação sejam reconhecidos e capilarizados pelos programas de pós-graduação e para além desse âmbito estrito. Não obstante, no cenário atual, a área, precisamente por constituir a CAPES, vê-se obrigada a questionar frontalmente os critérios que estão sendo propostos para qualificação das revistas científicas. Tal como procuramos evidenciar, no âmbito da área, da maneira como tais critérios estão sendo impostos, fica fortemente comprometida a legitimidade de um dos mais importantes parâmetros de avaliação (qual seja, a avaliação da produção científica), dado se basear em critérios arbitrários e pretensamente imparciais.

Finalmente, alertamos as agências de fomento, universidades e nossos próprios pares, para o fato de que a classificação de periódicos feita com base nessas restrições artificialmente impostas não corresponde à avaliação de mérito efetivamente feita pela área ou pela própria CAPES, não podendo, portanto, servir de base para a avaliação da produção de pesquisadores, grupos e instituições tal como se apresenta.

\section{Vitória, I e 2 de outubro de 2008}

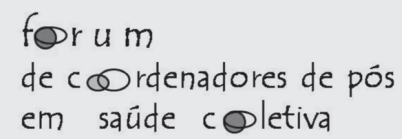

